\title{
Negative life events, cognitive emotion regulation and emotional problems
}

\author{
N. Garnefski*, V. Kraaij, P. Spinhoven \\ Department of Psychology, Division of Clinical and Health Psychology, University of Leiden, PO Box 9555, \\ 2300 Leiden, The Netherlands
}

Received 22 October 1999; received in revised form 26 April 2000; accepted 25 May 2000

\begin{abstract}
A new questionnaire, named the Cognitive Emotion Regulation Questionnaire, has been constructed, measuring nine cognitive coping strategies people tend to use after having experienced negative life events. A test-retest design was used to study the psychometric properties and relationships with measures of depression and anxiety among 547 high school youngsters. Principal component analyses supported the allocation of items to subscales, while alphas of most subscales exceeded 0.80. Cognitive coping strategies were found to play an important role in the relationship between the experience of negative life events and the reporting of symptoms of depression and anxiety. The results suggest that cognitive coping strategies may be a valuable context of prevention and intervention (C) 2001 Elsevier Science Ltd. All rights reserved.
\end{abstract}

Keywords: Negative life events; Cognitive coping; Emotion regulation; Depression; Anxiety

\section{Introduction}

Emotion regulation is assumed to be an important factor in determining well being and/or successful functioning (Cicchetti, Ackerman \& Izard, 1995; Thompson, 1991). The general concept of emotion regulation can be understood as "all the extrinsic and intrinsic processes responsible for monitoring, evaluating and modifying emotional reactions, especially their intensive and temporal features, to accomplish one's goals" (Thompson, 1994, p. 27). According to this definition, the concept of emotion regulation is a very broad conceptual rubric encompassing many regulatory processes, such as the regulation of emotions by oneself versus the regulation of emotions by others and the regulation of the emotion itself versus the regulation of its underlying

* Corresponding author. Tel.: +31-71-5273774; fax: +31-71-5273619.

E-mail address: garnefski@fsw.leidenuniv.nl (N. Garnefski). 
features (Thompson \& Calkins, 1996). Emotion regulation, therefore, can refer to a wide range of biological, social, behavioral as well as conscious and unconscious cognitive processes. For example, in a physiological way, emotions are self-regulated by a rapid pulse, increased breathing rate (or shortness of breath), perspiration or other concomitants of emotional arousal. In a social way, emotions are regulated by seeking access to one's interpersonal and material support resources, while in a behavioral way emotions are regulated through a variety of behavioral (coping) responses. Shouting, screaming, crying or withdrawing are examples of behaviors displayed to manage the emotions arisen in response to a stressor. Finally, emotions can also be managed by a range of unconscious cognitive processes, such as selective attention processes, memory distortions, denial, or projection or by more conscious cognitive (coping) processes, such as blaming oneself, blaming others, ruminating or catastrophizing.

Although the concept is very useful as a theoretical description or explanation of the emotion system, the total process of emotion regulation is too complex and too broad to enable us to empirically focus on all aspects, mechanisms and processes at once. In this article we will restrict ourselves to the self-regulatory, conscious, cognitive components of emotion regulation. Although not many studies have explicitly been addressed to this aspect of emotion regulation, conscious cognitive components of emotion regulation have generated some interest in the form of research activities focused on coping strategies. Remarkably, however, cross-referencing between studies on emotion regulation and studies on coping, is scarce.

\subsection{Coping as an aspect of emotion regulation}

The general definition of coping is given by Monat and Lazarus (1991) as: "an individual's efforts to master demands (conditions of harm, threat or challenge) that are appraised (or perceived) as exceeding or taxing his or her resources" (p. 5). In our opinion, according to this definition, all coping efforts by an individual come under the broad definition of emotion regulation. In general, two major functions of coping are distinguished: problem-focused coping and emotionfocused coping. Whereas problem-focused coping strategies refer to attempts to act on the stressor, emotion-focused coping refers to attempts to manage the emotions associated with the stressor (Compas, Orosan \& Grant, 1993). Generally speaking, acting directly on the stressor by problemfocused coping is considered a more effective coping strategy than emotion-focused coping. Nevertheless, it is also acknowledged that under certain conditions, e.g. a situation in which nothing useful can be done to change it, problem-focused coping strategies may fail or even be counterproductive. In such situations emotion-focused coping efforts would be a better strategy (Lazarus, 1993).

Although most stressors may elicit both types of coping, problem-focused coping tends to predominate when people feel that something constructive can be done, whereas emotion-focused coping tends to predominate when people feel nothing can be done about the stressor (Carver, Scheier \& Weintraub, 1989).

Even though the operationalization of coping by the distinction between problem-focused and emotion-focused coping strategies is widely accepted and most coping measures are based on it, this approach gives rise to a number of conceptual problems:

1. Data analyses on most coping measures show that far more factors can be distinguished than just the two (Parker \& Endler, 1992). Often largely differing in character, these 'sub' 
factors (of which most are seen as variations on emotion-focused coping) sometimes have been shown to even have opposite adaptational outcomes. Examples of two such very different emotion-focused coping strategies are 'denial' on the one hand and 'social support seeking' on the other hand.

2. Another conceptual problem, associated with the former, is that the division into problemfocused and emotion-focused coping is not the only dimension by which coping strategies can be 'classified'. In fact, another important dimension crosses the boundaries of this division, i.e. the cognitive (what you think) versus the behavioral (what you do) strategies. Therefore, the fact that in most current measures, coping strategies can both be carried out through either cognitive or behavioral channels, is confusing. An example of problemfocused coping in a cognitive way is 'planning'; an example of problem-focused coping in a behavioral way is 'taking direct actions'. Examples of cognitive versus behavioral expressions of emotion-focused coping are, again, respectively 'denial' and 'social support seeking'.

In our opinion it is not appropriate to range the concepts of cognitive and behavioral coping strategies in one and the same dimension, as thinking and acting are two different processes employed at different points in time. According to this line of reasoning, the problem of cognitive and behavioral dimensions crossing the boundaries of the dimensions prevailing in the literature might inhibit coping research. It seems reasonable to assume that cognitive appraisal processes although not necessarily in a conscious way - precede the process of taking action. For example, first 'plans are made to take action', subsequently 'action is taken'. Therefore, from the point of view of intervention, it is more fruitful to teach people to plan their actions and subsequently act in a conscious way than to teach them to take immediate actions without focusing on the accompanying cognitions.

In order to measure them in a conceptually pure way, we need to measure cognitive coping strategies separately, while excluding the dimension of behavioral strategies. The aim of the present study is to focus on this cognitive part of coping strategies.

\subsection{Cognitive emotion regulation}

In this study, the terms 'cognitive coping' and 'cognitive emotion regulation' are used as interchangeable terms. Generally speaking, both concepts can be understood as the cognitive way of managing the intake of emotionally arousing information (Thompson, 1991). The regulation of emotions through cognitions is inextricably associated with human life. Cognitions or cognitive processes may help us to manage or regulate emotions or feelings, and to keep control over our emotions and/or not getting overwhelmed by them, for example, during or after the experience of threatening or stressful events.

As we have stated above, until now cognitive coping or the cognitive components of emotion regulation have not been studied separately from other coping dimensions. As a consequence although there has been a considerable interest in cognitive processes as regulators of other developmental processes — we do not know much about how cognitive processes regulate emotions and how this may affect the course of emotional development.

To be able to provide an answer to questions such as whether and to what extent certain cognitions regulate emotions, a standard measure should be developed that measures cognitive 
emotion regulation strategies. As such a measure was not available yet, this study reports on its development. To guide the scale's content, we have used a theory-based or 'rational' approach. In defining and clarifying the dimensions of cognitive coping we made use of existing measures of coping (de Ridder, 1997). Our strategy has been to consider coping strategies from existing measures, either by taking out and reformulating the cognitive dimensions (as far as they existed), by 'transforming' non-cognitive coping strategies into cognitive dimensions or by adding new strategies on 'rational' grounds, for which we especially consulted and/or made use of the COPE (Carver et al., 1989), the Coping Inventory for Stressful Situations (CISS; Endler \& Parker, 1990, 1994; Parker \& Endler, 1992) and the Ways of Coping Questionnaire (WCQ; Folkman \& Lazarus, 1988).

\subsection{Dimensions of cognitive emotion regulation}

The instrument we developed includes nine conceptually distinct scales, each consisting of four items and each referring to what you think and not to what you actually do following the experience of threatening or stressful life events.

\subsubsection{Self blame}

Self-blame refers to thoughts of blaming yourself for what you have experienced. Although inconsistent findings as regards the exact relationship have been produced, most studies have shown that an attributional style of self-blaming is related to depression and other measures of ill-health (Anderson, Miller, Riger, Dill \& Sedikides, 1994). Despite the fact that some of the items of the WCQ subscale 'accepting responsibility' are conceptually comparable to our instrument, the concept as a whole is not, as the WCQ contains both cognitive and behavioral items in one and the same subscale. As regards the CISS: whereas items such as 'I blame myself for having gotten into this situation' are included, self-blame is not distinguished as a separate concept in this instrument. Instead, it is a part of the concept of 'Emotion-oriented Coping', which includes a broad range of emotion-focused thoughts and behaviors (including items such as getting angry or feeling anxious). A one-item subscale of 'blaming self' can be found in the 'Kidcope' (Spirito, Stark \& Williams, 1988).

\subsubsection{Blaming others}

Blaming others refers to thoughts of putting the blame of what you have experienced on others. Studies have shown that across samples having experienced different forms of threatening events, blaming someone else is associated with poorer emotional well being (Tennen \& Affleck, 1990). A one-item subscale of 'blaming others' can be found in the 'Kidcope' (Spirito et al., 1988). The ACOPE includes one item referring to blaming others, but this item is part of the broader concept of 'ventilating feelings' (Patterson \& McCubbin, 1987).

\subsubsection{Acceptance}

Acceptance refers to thoughts of accepting what you have experienced and resigning yourself to what has happened. Carver et al. (1989) have shown that acceptance as a coping strategy (largely comparable to our definition of acceptance) has a moderately positive relationship with measures of optimism and self-esteem and a (moderately) negative relationship with measures of anxiety. The items in our subscale of 'acceptance' are based on a rephrasing of items in the subscale 'acceptance' of the COPE. It could be argued that in most cases acceptance can be considered 
a functional coping response, as accepting the reality of the situation implies a certain attempt to deal with that situation.

\subsubsection{Refocus on planning}

Refocus on planning refers to thinking about what steps to take and how to handle the negative event. It is the cognitive part of action-focused coping, which does not automatically imply that actual behavior will follow. Action-focused coping strategies are included in all existing coping questionnaires. The WCQ distinguishes confrontive coping (aggressive efforts to alter the situation) and planful problem solving. Planful problem solving consists of both cognitivefocused items (analytic approaches to solving the problem) and behavioral-focused items (problem-focused efforts to alter the situation). The COPE also distinguishes two dimensions of problem-focused coping: a behavioral-focused dimension (active coping) and a cognitive-focused dimension (planning). The content of 'planning' (thinking about how to cope with a stressor) is comparable to the content of our concept of 'planful thinking'. The CISS includes the dimension of 'task-oriented coping', consisting of a mixture of cognitive and behavioral items. Carver et al. (1989) have shown that using 'planning' as a coping strategy is positively related to measures of optimism and self-esteem and negatively to anxiety.

\subsubsection{Positive refocusing}

Positive refocusing refers to thinking about joyful and pleasant issues instead of thinking about the actual event. Refocusing on positive things can be considered a form of 'mental disengagement' and can be defined as turning or refocusing thoughts to more positive issues in order to think less about the actual event. It can be argued that refocusing thoughts to more positive issues could be considered a helpful response in the short term; it might, however, impede adaptive coping in the long term. Whereas the COPE also has a subscale called 'mental disengagement' and the WCQ has a subscale called 'escape/avoidance' which can also be considered as a form of 'mental disengagement', both subscales are almost exclusively focused on the behavioral dimension. Although the avoidance-oriented coping subscale of the CISS does include the item 'thinking about the good times I've had', here, too, the majority of items belonging to the scale are behavioral oriented ('go out for a walk').

\subsubsection{Rumination or focus on thought}

Rumination or focus on thought refers to thinking about the feelings and thoughts associated with the negative event. It has been shown that a ruminative coping style tends to be associated with higher levels of depression (Nolen-Hoeksema, Parker \& Larson, 1994). In the coping instruments consulted, rumination as such has not been included. Some elements of the concept are included in emotion-focused coping subscales, such as 'ventilation of feelings' (COPE, A-COPE).

\subsubsection{Positive reappraisal}

Positive reappraisal refers to thoughts of attaching a positive meaning to the event in terms of personal growth. Carver et al. (1989) have shown that using 'positive reappraisal' as a coping strategy is positively related to measures of optimism and self-esteem and negatively to anxiety. The WCQ also includes a 'positive reappraisal' dimension. Unlike in our concept, though, in their concept religious thoughts are included. The KIDCOPE includes a one-item scale called 'cognitive 
restructuring' (Spirito et al., 1988). The COPE has the comparable concept of 'positive reinterpretation and growth', which is also exclusively focused on reappraisal of stressful events in positive terms. The items of our subscale of 'positive reappraisal' are based on a rephrasing of the items of this COPE subscale.

\subsubsection{Putting into perspective}

Putting into perspective refers to thoughts of playing down the seriousness of the event or emphasizing its relativity when compared to other events. Although it has been shown that the concept of (social) comparison is an important issue in relation to different types of psychopathology (Allan \& Gilbert, 1995), as yet the concept has not been included as such in any of the coping measures, neither as a scale, nor as an item.

\subsubsection{Catastrophizing}

Catastrophizing refers to thoughts of explicitly emphasizing the terror of an experience. In general, a catastrophizing style appears to be related to maladaptation, emotional distress and depression (e.g. Sullivan, Bishop \& Pivik, 1995). None of the coping measures we consulted, however, include items referring to catastrophizing thoughts.

\subsection{The Cognitive Emotion Regulation Questionnaire (CERQ)}

A new questionnaire has been constructed, measuring the above-mentioned nine cognitive strategies of emotion regulation. The questionnaire has been named the Cognitive Emotion Regulation Questionnaire (CERQ). During the developmental phase we performed a number of pilot studies, starting with an initial pool of 40 items. During this process, items with weak loadings were revised or discarded. After various stages of refinement, a total set of 36 items remained, some of which have been determined early in the process and others later on. The CERQ can be used to measure cognitive strategies that characterize the individual's style of responding to stressful events as well as cognitive strategies that are used in a particular stressful event or situation, depending on the nature of the questions under study. The CERQ is designed to be a self-report questionnaire that can be administered to people aged 12 years and older as from that age people can be considered to have the cognitive abilities to grasp the meaning of the items.

Aim of the present study is to report on the factor structure, the alphas, test-retest reliabilities, and inter-scale correlations of the CERQ as well as on the correlations between CERQ scales and measures of ill-health, on the basis of a general population sample comprising about 550 adolescents. The subscales as tested in this study were used to measure relatively stable dispositional cognitive emotion regulation strategies.

\section{Method}

\subsection{Participants}

At first measurement, the sample comprised 547 12-16-year-old secondary school students (mean age 13 years and 8 months), attending a state school in The Netherlands. The sample consisted of 
$41.7 \%$ boys and $58.3 \%$ girls, while $19 \%$ attended lower general secondary education (MAVO), $42 \%$ higher general secondary education (HAVO) and 39\% pre-university education (VWO). The sample consisted of $6.2 \%$ pupils coming from ethnic minorities. As regards their home situations: $91.6 \%$ of the sample were living in intact families (father, mother and children), 7.3\% were living in one-parent families and $1.1 \%$ were living in other 'home' settings (foster parents, foster home, with others).

Of the initial population, 487 students $(89 \%)$ participated in the second measurement. At the follow-up, there were $41.1 \%$ boys and $58.9 \%$ girls with a mean age of 13 years and 11 months, of whom 21, 41 and 38\%, respectively, attended the MAVO, HAVO and VWO school types. The other sample characteristics were equal to the characteristics at first measurement.

\subsection{Design and procedure}

The research was carried out in three different state schools by means of a written questionnaire that the students filled out during school hours (about $25 \mathrm{~min}$ in total), under the supervision of a teacher and two graduate psychology students. The students were guaranteed anonymity in relation to their parents, teachers and fellow students. The first measurement took place in November 1998, the follow-up 5 months later.

\subsection{Materials}

The questionnaire covered a number of areas. This paper will report on measures of cognitive emotion regulation, depression and anxiety.

\subsubsection{Cognitive emotion regulation}

The CERQ was used to assess what participants tend to think after experiencing threatening or stressful life events. The following instruction was written down:

Everyone gets confronted with negative or unpleasant events now and then and everyone responds to them in his or her own way. By the following questions you are asked to indicate what you generally think, when you experience negative or unpleasant events.

The CERQ consists of 36 items. The answer categories for each of the items range from 1 [(almost) never] to 5 [(almost) always]. On the theoretical basis, nine subscales can be distinguished, each consisting of four items. A subscale score can be obtained by adding up the four items (range: from 4 to 20).

\subsubsection{Depression and anxiety}

Depression and anxiety were measured by two subscales of the Symptom Check List-90 (SCL: Derogatis, 1977; Dutch translation and adaptation by Arrindell and Ettema, 1986). The depression subscale consists of 15 items (item concerning loss of sexual interest was dropped, because of the age of the subjects), assessing whether and to what extent the participants report symptoms of depression; the anxiety subscale consists of 10 items, assessing whether and to what extent participants report symptoms of anxiety. Answer categories of the items range from 1 (not at all) to 5 (very much). Scale scores are obtained by summing the items belonging to the scale. Previous 
studies have reported alpha-coefficients ranging from 0.82 to 0.93 for depression and from 0.71 to 0.91 for anxiety. In addition, test-retest reliabilities are found to be good and both subscales have been found to show strong convergent validity with other conceptually related scales (Arrindell \& Ettema). In the present sample alpha coefficients were found of 0.87 and 0.80 for depression and anxiety, respectively, with a mean of 6.57 depression symptoms (S.D. $=6.73$ ) and a mean of 3.72 anxiety symptoms (S.D. $=3.93)$ at follow-up.

\section{Results}

\subsection{Principal component analyses (PCAs)}

Two PCAs were performed, with oblimin rotation to allow for correlations among factors: (1) on the data of the first measurement; and (2) on the data of the follow-up. After the first measurement, seven items were revised or replaced. The item set presented in Table 1 refers to the final 36-item set used for follow-up measurement. The factor loadings listed in the third and fourth column of Table 1 are the correlations between the items and the factors on the base of the factor structure matrices of the first and second measurement, respectively. For the sake of comparability, the PCA concerning first measurement was performed on the 29 items (eight scales) that had remained stable across the two measurements (36 minus the seven replaced ones). The PCA concerning follow-up included all 36 items and all nine scales.

As regards the results of first measurement: we extracted eight factors (seven factors had an eigenvalue $>1$, one factor had an eigenvalue of 0.99 ). Together they explained $63.2 \%$ of the variance. Communalities of the variables ranged between 0.53 and 0.75 . The factors were fully in accord with the a priori assignment of items to the scales. As regards the factor loadings of the first measurement (third column Table 1): for each item, except for one, the conclusion held that its highest loading was on the scale to which it theoretically belonged. The exception was for the item 'I look for the positive sides to the matter' that obtained a relatively 'weak' (compared to the other loadings) loading of -0.41 on its a priori 'positive reappraisal' scale and a relatively high loading (not in the table) of 0.61 on the 'refocus on planning' subscale. All other loadings on the a priori factors exceeded 0.54.

As regards follow-up, we extracted nine factors (eight factors had an eigenvalue $>1$, the ninth factor had an eigenvale of 0.99 ), together explaining $64.6 \%$ of the variance with communalities ranging between 0.46 and 0.73 . Here, too, the factor structure and factor loadings were in accord with the a priori subscales (fourth column of Table 1). Only for the subscale 'positive reappraisal' it appeared that the items 'I think I can learn something from the situation' and 'I think that I can become a stronger person...' obtained relatively weak loadings ( 0.36 and 0.13 , respectively) on their a priori 'positive reappraisal' scale and relatively high loadings (0.68 and 0.64$)$ on the 'refocus on planning' subscale. In all other cases, the highest loadings (all exceeding 0.57) were found on the scales to which they theoretically belonged.

\subsection{Correlations between subscales}

Correlations between subscales ranged between 0.20 ('catastrophizing' and 'putting into perspective') and 0.62 ('positive reappraisal' and 'refocus on planning') with a mean Pearson 
Table 1

Factor structure of the Cognitive Emotion Regulation Questionnaire; items listed by a priori assignment to subscales

\begin{tabular}{|c|c|c|c|}
\hline \multirow[t]{2}{*}{ Scale name } & \multirow[t]{2}{*}{ Items } & \multicolumn{2}{|c|}{ Factor loadings } \\
\hline & & $\begin{array}{l}\text { First } \\
\text { measurement }\end{array}$ & Follow-up \\
\hline Self-blame & $\begin{array}{l}\text { - I feel that I am the one to blame for it } \\
\text { - I feel that I am the one who is responsible for what has happened } \\
\text { - I think about the mistakes I have made in this matter } \\
\text { - I think that basically the cause must lie within myself }\end{array}$ & $\begin{array}{l}0.77 \\
0.74 \\
0.54 \\
0.82\end{array}$ & $\begin{array}{l}0.76 \\
0.82 \\
0.69 \\
0.85\end{array}$ \\
\hline Acceptance & $\begin{array}{l}\text { - I think that I have to accept that this has happened } \\
\text { - I think that I have to accept the situation } \\
\text { - I think that I cannot change anything about it } \\
\text { - I think that I must learn to live with it }\end{array}$ & $\begin{array}{l}\text { Revised } \\
0.61 \\
0.77 \\
0.77\end{array}$ & $\begin{array}{l}-0.79 \\
-0.78 \\
-0.67 \\
-0.80\end{array}$ \\
\hline Focus on thought/rumination & $\begin{array}{l}\text { - I often think about how I feel about what I have experienced } \\
\text { - I am preoccupied with what I think and feel about what I have experienced } \\
\text { - I want to understand why I feel the way I do about what I have experienced } \\
\text { - I dwell upon the feelings the situation has evoked in me }\end{array}$ & $\begin{array}{l}0.78 \\
0.80 \\
0.74 \\
0.77\end{array}$ & $\begin{array}{l}-0.84 \\
-0.84 \\
-0.73 \\
-0.75\end{array}$ \\
\hline Refocus on planning & $\begin{array}{l}\text { - I think of what I can do best } \\
\text { - I think about how I can best cope with the situation } \\
\text { - I think about how to change the situation } \\
\text { - I think about a plan of what I can do best }\end{array}$ & $\begin{array}{l}0.60 \\
0.69 \\
0.63 \\
0.74\end{array}$ & $\begin{array}{l}0.68 \\
0.68 \\
0.57 \\
0.62\end{array}$ \\
\hline Positive reappraisal & $\begin{array}{l}\text { - I think I can learn something from the situation } \\
\text { - I think that I can become a stronger person } \\
\text { as a result of what has happened } \\
\text { - I think that the situation also has its positive sides } \\
\text { - I look for the positive sides to the matter }\end{array}$ & $\begin{array}{l}-0.77 \\
-0.72 \\
-0.66 \\
-0.41\end{array}$ & $\begin{array}{l}0.36 \\
0.13 \\
0.69 \\
0.64\end{array}$ \\
\hline
\end{tabular}


Table 1 (continued)

\begin{tabular}{|c|c|c|c|}
\hline \multirow[t]{2}{*}{ Scale name } & \multirow[t]{2}{*}{ Items } & \multicolumn{2}{|c|}{ Factor loadings } \\
\hline & & $\begin{array}{l}\text { First } \\
\text { measurement }\end{array}$ & Follow-up \\
\hline Putting into perspective & $\begin{array}{l}\text { - I think that it all could have been much worse } \\
\text { - I think that other people go through much worse experiences } \\
\text { - I think that it hasn't been too bad compared to other things } \\
\text { - I tell myself that there are worse things in life }\end{array}$ & $\begin{array}{l}-0.75 \\
-0.86 \\
-0.75 \\
\text { Revised }\end{array}$ & $\begin{array}{l}0.79 \\
0.74 \\
0.64 \\
0.72\end{array}$ \\
\hline Catastrophizing & $\begin{array}{l}\text { - I often think that what I have experienced is much worse than } \\
\text { what others have experienced } \\
\text { - I keep thinking about how terrible it is what I } \\
\text { have experienced } \\
\text { - I often think that what I have experienced is the worst that can } \\
\text { happen to a person } \\
\text { - I continually think how horrible the situation has been }\end{array}$ & $\begin{array}{l}\text { Revised } \\
\text { Revised } \\
\text { Revised } \\
\text { Revised }\end{array}$ & $\begin{array}{l}0.62 \\
0.73 \\
0.78 \\
0.67\end{array}$ \\
\hline Blaming others & $\begin{array}{l}\text { - I feel that others are to blame for it } \\
\text { - I feel that others are responsible for what has happened } \\
\text { - I think about the mistakes others have made in this matter } \\
\text { - I feel that basically the cause lies with others }\end{array}$ & $\begin{array}{l}0.76 \\
0.72 \\
0.66 \\
0.76\end{array}$ & $\begin{array}{l}-0.80 \\
-0.59 \\
-0.46 \\
-0.82\end{array}$ \\
\hline
\end{tabular}


correlation coefficient of 0.42 . This indicates moderate to strong correlations between the subscales (Table 2).

To summarize the correlations among scales, second-order PCA was performed on the followup data, with the subscales as variables. Two factors were extracted with eigenvalues larger than 1 , with a total explained variance of $60.4 \%$. The first factor consisted of the 'theoretically more adaptive' subscales: positive refocusing, positive reappraisal, putting into perspective, refocus on planning and acceptance, and was interpreted as: 'positive-focused cognitive emotion regulation'. The second factor consisted of the 'theoretically less adaptive' subscales: rumination, self-blame, blaming others and catastrophizing, and was interpreted as 'negative-focused cognitive emotion regulation'.

The one-factor model explained a total amount of variance of $48.5 \%$ and may be interpreted as 'use of cognitive emotion regulation strategies'.

\subsection{Reliabilities of the scales (alpha and test-retest)}

Cronbach's alpha reliability coefficients were computed for both measurements (Table 3). As regards first measurement, computation was done with only the eight subscales including the items that had remained across the two measurements. Follow-up computation was done on all nine scales all including four items. In general, alpha reliabilities at first measurement were acceptably high. Only the subscales of 'acceptance' and 'positive refocusing' had alphas below 0.70 . However, this had been expected, as both subscales were based on a total item set of three items and were supplemented with a revised fourth item at follow-up. The reliabilities of the 'positive-focused' and the 'negative-focused' subscales at first measurement (constructed on the basis of second-order PCA of the follow-up data) were good: respectively, 0.89 and 0.82 . The reliability of the total scale ('use of cognitive emotion regulation strategies') was 0.92 .

At follow-up, the alpha reliabilities of the subscales ranged from 0.68 to 0.83 . Five of the alphas appeared to be higher than 0.80 , while only one was below 0.70 . For the total 'positive', 'negative' and 'cognitive' scales, alpha reliabilities of $0.91,0.87$ and 0.93 were found.

Test-retest reliability coefficients were determined by computing Pearson correlations between subscale scores of first and second measurement (Table 3). As regards the subscales that were revised after the first measurement: test-retest correlations were calculated by computing Pearson correlations between the three-item-subscale score of the first measurement and the four-itemsubscale score of the follow-up. The values referring to revised subscales are shown between brackets and should be considered as no more than approximations of the test-retest reliabilities.

Taking into consideration the 5-month follow-up period, (approximations of) the test-retest reliabilities of the subscales were found to be adequate to good with values ranging between 0.41 and 0.59 . The lowest test-retest correlation was found for one of the revised subscales: 'acceptance'. The total 'positive', 'negative' and 'cognitive' scales yielded correlations of $0.62,0.62$ and 0.64 , respectively.

\subsection{Means and standard deviations at follow-up}

Table 3 also displays the means and standard deviations of the CERQ scales at follow-up. In general, the theoretically more adaptive cognitive coping strategies (such as positive reappraisal 
Table 2

Pearson intercorrelations between Cognitive Emotion Regulation Questionaire (CERQ) scales at follow-up

\begin{tabular}{|c|c|c|c|c|c|c|c|c|}
\hline $\begin{array}{l}\text { CERQ } \\
\text { subscales }\end{array}$ & Self-blame & Acceptance & Rumination & $\begin{array}{l}\text { Positive } \\
\text { refocusing }\end{array}$ & $\begin{array}{l}\text { Refocus on } \\
\text { planning }\end{array}$ & $\begin{array}{l}\text { Positive } \\
\text { reappraisal }\end{array}$ & $\begin{array}{l}\text { Putting into } \\
\text { perspective }\end{array}$ & Catastrophizing \\
\hline Self-blame & - & - & - & - & - & - & - & - \\
\hline Acceptance & $0.49 * * *$ & - & - & - & - & - & - & - \\
\hline Rumination & $0.55 * * *$ & $0.55 * * *$ & - & - & - & - & - & - \\
\hline $\begin{array}{l}\text { Positive } \\
\text { refocusing }\end{array}$ & $0.25 * * *$ & $0.46^{* * *}$ & $0.29 * * *$ & - & - & - & - & - \\
\hline $\begin{array}{l}\text { Refocus on } \\
\text { planning }\end{array}$ & $0.52 * * *$ & $0.37 * * *$ & $0.56 * * *$ & $0.37 * * *$ & - & - & - & - \\
\hline $\begin{array}{l}\text { Positive } \\
\text { reappraisal }\end{array}$ & $0.44 * * *$ & $0.43^{* * *}$ & $0.43 * * *$ & $0.43 * * *$ & $0.62 * * *$ & - & - & - \\
\hline $\begin{array}{l}\text { Putting into } \\
\text { perspective }\end{array}$ & $0.44 * * *$ & $0.49 * * *$ & $0.41 * * *$ & $0.49 * * *$ & $0.48 * * *$ & $0.52 * * *$ & - & - \\
\hline Castastrophizing & $0.34 * * *$ & $0.37 * * *$ & $0.51 * * *$ & $0.23 * * *$ & $0.29 * * *$ & $0.22 * * *$ & $0.20 * * *$ & - \\
\hline Blaming others & $0.34 * * *$ & $0.35 * * *$ & $0.39 * * *$ & $0.31 * * *$ & $0.40 * * *$ & $0.39 * * *$ & $0.39 * * *$ & $0.43 * * *$ \\
\hline
\end{tabular}

$* * * P<0.001$

Table 3

Scale properties of the Cognitive Emotion Regulation Questionnaire (CERQ) Cronbach's alpha reliabilities; test-retest reliabilities; means and standard deviations (at follow-up)

\begin{tabular}{|c|c|c|c|c|c|}
\hline CERQ scales & $\alpha$ First $(n=562)$ & $\alpha$ Follow-up $(n=487)$ & Test-retest $r(n=487)$ & $M$ (follow-up) & S.D. \\
\hline Self-blame & 0.73 & 0.81 & 0.54 & 7.27 & 2.87 \\
\hline Acceptance & 0.66 (3 items) & 0.80 & $(0.41)$ & 9.01 & 3.36 \\
\hline Rumination & 0.81 & 0.83 & 0.63 & 8.18 & 3.37 \\
\hline Positive refocusing & 0.66 (3 items) & 0.81 & $(0.54)$ & 9.25 & 3.40 \\
\hline Refocus on planning & 0.81 & 0.81 & 0.59 & 9.74 & 3.44 \\
\hline Positive reappraisal & 0.74 & 0.72 & 0.52 & 8.63 & 2.98 \\
\hline Putting into Perspective & 0.74 (3 items) & 0.79 & 0.50 & 9.29 & 3.38 \\
\hline Catastrophizing & - & 0.72 & - & 5.83 & 2.29 \\
\hline Blaming others & 0.71 & 0.68 & 0.48 & 5.99 & 2.06 \\
\hline Total 'positive' & 0.89 (17 items) & 0.91 (20 items) & $(0.62)$ & 45.65 & 12.24 \\
\hline Total 'negative' & 0.82 (12 items) & 0.87 (16 items) & $(0.62)$ & 27.11 & 8.01 \\
\hline Total 'cognitive' & 0.92 (29 items) & 0.93 (36 items) & $(0.64)$ & 72.74 & 18.38 \\
\hline
\end{tabular}


or putting into perspective) were reported to have been used more often than the less adaptive coping strategies (such as rumination and self-blame). The highest mean score was found for the reporting of the cognitive coping strategy of 'refocus on planning' (reported most often). 'Blaming others' and 'catastrophizing' were reported to have been used as cognitive coping strategy less often.

\subsection{Correlations between CERQ subscales and SCL-90 measures of depression and anxiety at follow-up}

The first column of Table 4 presents the Pearson bivariate correlations between the CERQ subscales and scores of depression. As the CERQ subscales were interrelated, partial correlations were also calculated, referring to the correlation between CERQ subscale and outcome measures, controlling for each of the other CERQ subscales (the second column). The third and fourth column show the bivariate correlations and partial correlations between CERQ scales and scores of anxiety.

Pearson correlations between CERQ subscales and depression ranged between 0.09 (positive refocusing) and 0.55 (rumination). Without controlling for the influence of the other CERQ scales, all correlations between CERQ scales and depression were positive and significant. Especially, the cognitive strategies of 'rumination' and 'self-blame' tended to be strongly related to scores of depression. After controlling for the influence of the other strategies, only the cognitive strategies of rumination, self-blame, catastrophizing, positive refocusing and positive reappraisal remained significant. Rumination, self-blame and catastrophizing had a positive

Table 4

Pearson and partial intercorrelations between Cognitive Emotion Regulation Questionnaire (CERQ) scales and depression and anxiety symptoms at follow-up

\begin{tabular}{llllll}
\hline CERQ subscales & Depression & & & \multicolumn{2}{l}{ Anxiety } \\
\cline { 2 - 3 } \cline { 5 - 5 } & Pearson $r$ & Partial $r$ & & Pearson $r$ & Partial $r$ \\
\hline Self-blame & $0.46^{* * *}$ & $0.31^{* * *}$ & & $0.40^{* * *}$ & $0.23^{* * *}$ \\
Acceptance & $0.29^{* * *}$ & 0.00 & & $0.26^{* * *}$ & 0.00 \\
Rumination & $0.55^{* * *}$ & $0.44^{* * *}$ & & $0.54^{* * * *}$ & $0.44^{* * *}$ \\
Positive refocusing & $0.09^{*}$ & $-0.17^{* * *}$ & & $0.15^{* * *}$ & -0.07 \\
Refocus on planning & $0.28^{* * *}$ & -0.03 & & $0.29^{* * *}$ & 0.01 \\
Positive reappraisal & $0.17^{* * *}$ & $-0.16^{* * *}$ & & $0.20^{* * *}$ & $-0.10^{*}$ \\
Putting into perspective & $0.24^{* * *}$ & -0.04 & & $0.23^{* * *}$ & -0.04 \\
Catastrophizing & $0.35^{* * *}$ & $-0.21^{* * *}$ & & $0.26^{* * *}$ & $-0.10^{*}$ \\
Blaming others & $0.18^{* * *}$ & -0.04 & $0.16^{* * *}$ & -0.06 \\
Total 'positive' & $0.27^{* * *}$ & $-0.11^{* *}$ & & $0.29^{* * *}$ & -0.03 \\
Total 'negative' & $0.53^{* * *}$ & $0.48^{* * *}$ & & $0.48^{* * *}$ & $-0.39^{* * *}$ \\
Total 'cognitive' & $0.41^{* * *}$ & - & $0.40^{* * *}$ & -
\end{tabular}

\footnotetext{
$* P<0.05$.

$* * P<0.01$.

$* * * P<.001$.
} 
relationship with depression, which means that the more respondents reported these strategies, the more depressive symptoms they reported. After controlling for the other strategies, positive refocusing and positive reappraisal had negative relationships with depression, which means that the more respondents reported to use these strategies, the less depressive symptoms they reported.

As regards the total 'positive', 'negative' and 'cognitive' scales, it also appeared that before controlling there was a significant, positive correlation with depression. After controlling for the total scale of 'negative' cognitive coping, the sign of the correlation of 'positive' cognitive coping with depression reversed to negative. This implies that while the use of 'positive' strategies is related to the reporting of a lower extent of depressive symptoms, the use of 'negative' strategies is related to the reporting of a higher extent.

Also, all Pearson correlations between CERQ subscales and anxiety were positive and significant, ranging between 0.15 (positive refocusing) and 0.54 (rumination). Here, too, the cognitive strategies of 'rumination' and 'self-blame' showed the highest correlations. After controlling, rumination, self-blame, catastrophizing and positive reappraisal remained significant. Reporting rumination, self-blame or catastrophizing as a cognitive strategy was related to reporting more symptoms of anxiety, while reporting positive reappraisal as a strategy was related to reporting lower levels of anxiety.

Before controlling, the total scales also had a significant, positive correlation with anxiety. After controlling for 'negative' cognitive coping, the correlation between 'positive' cognitive coping and depression was no longer significant. This implies that while the use of 'negative' strategies is related to the reporting of a higher extent of anxiety symptoms, the use of 'positive' strategies is not uniquely related to the reporting of a lower extent of anxiety symptoms.

\section{Discussion}

In this study a new instrument, called the Cognitive Emotion Regulation Questionnaire (CERQ), has been developed to assess people's cognitive emotion regulation strategies. It is the first inventory that focuses exclusively on the cognitive part of coping, thus crossing the boundaries of problem-focused versus emotion-focused coping. Nine different cognitive strategies were distinguished on rational bases. The results of PCA provided empirical support to the allocation of items to subscales, while the reliabilities of the scales were good with most alphas exceeding 0.80. The test-retest reliabilities suggested that cognitive coping strategies are relatively stable styles, although they do not appear to be equally stable as personality traits.

It was shown that the cognitive coping strategies could in part be traced to one common underlying (extent of cognitive coping) dimension and in part be split up into two separate strategy types, i.e. the theoretically 'more adaptive' strategies (i.e. positive refocusing, positive reappraisal, putting into perspective, refocus on planning and acceptance) and the theoretically 'less adaptive' strategies (i.e. rumination, self-blame, blaming others and catastrophizing). In general, the theoretically 'more adaptive' cognitive coping strategies were reported to have been used more often than the 'less adaptive' coping strategies. The cognitive coping strategy of 'refocus on planning' was reported most often. 'Blaming others' and 'catastrophizing' were reported less often to have been used as cognitive coping strategies. 
As regards the relationship with the outcome measures, the positive bivariate correlations between all nine cognitive strategies and depression and anxiety, suggests the conclusion that the more often an individual reports the use of cognitive coping strategies in general, the more depression and/or anxiety symptoms he or she reports. However, after controlling for the influence of the other strategies, an important and very interesting shift in the results became visible: namely that the theoretically 'more adaptive' strategies such as positive refocusing and positive reappraisal yielded negative relationships with depression and anxiety, which meant that the more often the respondents reported the use of 'more adaptive' strategies, the fewer depression and anxiety symptoms they reported. The relationship between rumination, self-blame and catastrophizing on the one hand and depression and anxiety on the other remained positive, which means that the more often the respondents reported to use the 'less adaptive' strategies, the more depression and anxiety symptoms they reported.

What are the theoretical implications of these results? Since Lazarus launched his cognitive appraisal model (Lazarus \& Folkman, 1984), the most widely used framework to classify coping responses has been the problem-focused versus emotion-focused model, despite some conceptual problems. One of the problems refers to the fact that both the problem- and emotion-focused dimensions are made up of a mix of cognitive and behavioral coping strategies (i.e. thinking and acting), while it would be reasonable to assume that, theoretically, cognitive coping and taking actions can be considered as very different processes. Our results suggest that theories about dysfunctioning should consider cognitive coping strategies and behavioral coping strategies in conceptually pure and distinct ways.

It was shown that depressive and anxious symptoms cannot be traced to one specific cognitive coping strategy, but to a combined 'play' of various strategies. Studies on the relation between cognitive coping and dysfunction should therefore not focus on a single cognitive coping strategy at the time, but on all cognitive coping strategies at the same time in order to be complete and of value. In addition, the results indicate the relevance of identifying (individual) symptom patterns crossing the boundaries of 'adaptive' and 'less adaptive' strategies. For example, there may exist large differences between adolescents who report different patterns of 'cognitive coping strategies', especially between adolescents who report predominantly 'less adaptive' strategies, adolescents who report predominantly 'more adaptive' strategies, adolescents who report both type of strategies and those who report that they make no or only scarce use of any of the cognitive coping strategies.

Although a clear relationship has been shown between the experience of negative life events, cognitive coping strategies and psychopathology, the present study does not allow one to draw conclusions about the directions of influence. Theoretically, it is just as likely that a certain cognitive coping strategy leads to emotional problems, as the other way around. Circular causal mechanisms may also be at work, which would make both assumptions true at the same time. Still, whatever the directions of influence may be: on the basis of the present study it might be argued that the use of certain cognitive coping strategies can be an important indicator of serious disturbances and, therefore, should play a general and central role in theoretical models explaining mental health problems.

A limitation of the design was that the detection of depression and anxiety symptoms as well as the assessment of cognitive coping strategies had to be made on the basis of self-reported evaluations, which may have caused some bias. The results of this study may be an under- or overestimation of the extent to which cognitive coping strategies are applied in reality. 
Further, in interpreting the findings it is important to realize that the study sample comprised predominantly 'normal' white secondary school students, aged between 12 and 16 years. In future research, it is important to reach other groups, too, because it is reasonable to assume that, for example, in adult samples or in clinical samples other patterns of cognitive coping strategies will be used: a cognitive coping strategy like catastrophizing, scarcely reported in the present sample, may yield other prevalence rates in a clinical sample. In addition, it is important to include samples comprising individuals who have experienced a specific negative life event or trauma, such as sexual abuse or war incidences.

To be able to further develop the concept of cognitive coping, it is important to answer questions such as whether strategies that are considered 'adaptive' in the present study are indeed adaptive in all circumstances. It may very well be true that a certain cognitive coping strategy that is highly adaptive in one situation, is absolutely not in another situation. In the present study the concept of cognitive coping is considered from a trait or style perspective. After adaptation of the introduction, it is very well possible to use the present instrument also for situation-specific cognitive coping. According to Lazarus (1993) both the approaches to coping as a style and as a situation-specific process are essential in that they each address different aspects of the coping process.

Furthermore, it is important to acknowledge that in the present design the reporting of certain cognitive coping strategies may be confounded with the reporting of depression and anxiety symptoms. It might also be argued that the relationships observed in this study could be spurious ones, i.e expressions of a third factor that was not measured in this study, such as genetic or personality factors.

A strong point in this study has been the use of a large general population sample within a testretest design in the development of a new questionnaire measuring cognitive coping strategies. Another important aspect is that, as far as we know, it is probably one of the first studies to empirically show that certain cognitive coping patterns may form an indication of the severity of mental ill-health.

An important direction of future research is to focus on establishing construct validity of the present measure on cognitive coping. To establish validity, studies should be performed on the relationships between the CERQ, existing coping measures and other related concepts (e.g. selfefficacy).

In conclusion, the complex relationship between the experience of stressful life events, cognitive emotion regulation and maladjustment seems an important direction for future research. The exploratory character of the results makes replication, thorough testing and further development (e.g. inclusion of other factors) necessary. Prospective elements should be included in the model. However, if our results can be confirmed, they may carry important implications for the focus and content of intervention and prevention of mental health problems.

\section{Acknowledgements}

We thank Denise Beuvens, Manon van Boekel, Natasja Buurman, Trea van Dijken, Marijenne van der Gaag, Nino Hochstenbach, Tessa van den Kommer, Lara Koppenaal, Jeroen Legerstee, Gea Smit, Lucie Timmers, Jan Teerds and Sarah Verheul, for their conscientious help in the process of data assembly. We thank Denise Beuvens for her comments on earlier drafts. 


\section{References}

Allan, S., \& Gilbert, P. (1995). A social comparison scale: psychometric properties and relationship to psychopathology. Journal of Personality and Individual Differences, 19, 293-299.

Anderson, C. A., Miller, R. S., Riger, A. L., Dill, J. C., \& Sedikides, C. (1994). Behavioral and characterological styles as predictors of depression and loneliness: review, refinement, and test. Journal of Personality and Social Psychology, $66,549-558$.

Arrindell, W. A. \& Ettema, J. H. M. (1986). SCL-90. Handleiding bij een multidimensionele psychopathologie-indicator [Manual for a multidimensional psychopathology-indicator/Dutch translation and adaptation]. Lisse, The Netherlands: Swets \& Zeitlinger

Carver, C. S., Scheier, M. F., \& Weintraub, J. K. (1989). Assessing coping strategies: a theoretically based approach. Journal of Personality and Social Psychology, 56, 267-283.

Cicchetti, D., Ackerman, B. P., \& Izard, C. E. (1995). Emotions and emotion regulation in developmental psychopathology. Development and Psychopathology, 7, 1-10.

Compas, B. E., Orosan, P. G., \& Grant, K. E. (1993). Adolescent stress and coping: implications for psychopathology during adolescence. Journal of Adolescence, 16, 331-349.

de Ridder, D. (1997). What is wrong with coping assessment A review of conceptual and methodological issues? Psychology and Health, 12, 417-431.

Derogatis, L. R. (1977). SCL-90: administration, scoring and procedures manual-I for the (revised) version. Baltimore: John Hopkins University School of Medicine, Clinical Psychometrics Research Unit.

Endler, N. S., \& Parker, J. D. A. (1990). Multidimensional assessment of coping: a critical evaluation. Journal of Personality and Social Psychology, 58, 844-854.

Endler, N. S., \& Parker, J. D. A. (1994). Assessment of multidimensional coping: task, emotion and avoidance strategies. Psychological Assessment, 6, 50-60.

Folkman, S., \& Lazarus, R. S. (1988). Manual of the Ways of Coping Questionnaire. Palo Alto: Consulting Psychologists Press.

Lazarus, R. S. (1993). Coping theory and research: past, present, and future. Psychosomatic Medicine, 55, 234-247.

Lazarus, R., \& Folkman, S. (1984). Stress, appraisal and coping. New York: Springer.

Monat, A., \& Lazarus, R. S. (1991). Stress and coping: an anthology. New York: Columbia University Press.

Nolen-Hoeksema, S., Parker, L. E., \& Larson, J. (1994). Ruminative coping with depressed mood following loss. Journal of Personality and Social Psychology, 67, 92-104.

Parker, J. D. A., \& Endler, N. S. (1992). Coping with coping assessment: a critical review. European Journal of Personality, 6, 321-344.

Patterson, J. M., \& McCubbin, H. I. (1987). Adolescent coping style and behaviors: conceptualization and measurement. Journal of Adolescence, 10, 163-186.

Spirito, A., Stark, L. J., \& Williams, C. (1988). Development of a brief coping checklist for use with pediatric populations. Journal of Pediatric Psychology, 13, 555-574.

Sullivan, M. J. L., Bishop, S. R., \& Pivik, J. (1995). The Pain Catastrophizing Scale: development and validation. Psychological Assessment, 7, 524-532.

Tennen, H., \& Affleck, G. (1990). Blaming others for threatening events. Psychological Bulletin, 108, 209-232.

Thompson, R. A. (1991). Emotional regulation and emotional development. Educational Psychology Review, 3, 269307.

Thompson, R. A. (1994). Emotional regulation: a theme in search for definition. In N. A. Fox, The development of emotion regulation: behavioral and biological considerations. Monographs of the Society for Research in Child Development, 59, 25-52

Thompson, R. A., \& Calkins, S. D. (1996). The double-edged sword: emotional regulation for children at risk. Development and Psychopathology, 8, 163-182. 